There does occur, however, the case where pus is shut up in the antrum and cannot escape owing to blocking of the natural ostium. In this case, which will be accompanied by very severe pain, intra-nasal puncture and suction of the antral contents with a Watson William's Syringe will relieve and may have to be repeated on several occasions.

As to the cause of these conditions, there is no doubt that they are in many cases associated with bathing and the causative organism is very frequently the hæmolytic streptococcus.

Watch must also be kept on the ears. It has been proved by experiment that the path of fluid evacuated from the normal ostium of a maxillary sinus lies over the eustachian cushion of the same side, hence it is easy to understand an accompanying Otitis.

The subsequent treatment of an Acute Sinusitis should not be neglected. Over douching of the nose is to be deprecated. A "Nasal Drill" may be carried out with safety. Some mildly antiseptic fluid such as Glycerin of Thymol (one in three of luke warm water) should be either sniffed up or gently poured up the nose out of a glass nasal douche, and then snorted out into a handkerchief or a piece of lint held away from the nose; in this way no intra-nasal pressure is created as in ordinary blowing of the nose. If this is done at bed-time the nose will probably remain clear most of the night.

After doing the "Drill" the introduction of a little plain vaseline will help to keep the passages clear.

\title{
THE CLINICAL PICTURE GALLERY IN MEDICAL EDUCATION
} BY C. O. HAWTHORNE, M.D. (GLASG.), F.R.C.P. (LOND.).

The purpose of this note is to propose that every medical school should include in its educational equipment a clinical picture gallery. There is no need to argue the force or value of the teaching appeal through the eye, for everyone admits it; and with not a few students visual memories are both more readily acquired and more persistent than are auditory memories. In the medical curriculum the professional lecture no longer dominates the training, and the pathological museum, the dissecting room, the physiological laboratory, the practical courses in chemistry, physics and biology, and the work of the clinical clerk and the surgical dresser all take a share in encouraging the student to educate himself by the observation of facts rather than by the hearing or reading of words. The clinical picture gallery would be an addition to this series, and the suggestion here made is that it would be a valuable addition. Admittedly, the best of all illustrations is the actual patient. But the significant patient is at the important moment by no means always available, and in these circumstances a not ineffective substitute may often be found in the clinical picture gallery.

The pictures themselves, at least in considerable numbers, already exist and await an opportunity for service. But they are shut up in bulky and relatively expensive atlases which the student either never sees or sees only on some passing and exceptional occasion. In his school picture gallery they would be part of his daily atmosphere and would secure that repetition of experiences which most of us need if memory is to be successfully impressed. If pathological facts in the shape of specimens in a museum need presentation of this order, why not also clinical facts in the shape of a picture gallery? 
There is indeed a special claim for such illustrations in addition to the repeated pictorial lessons they convey: this is their ability to supplement and complete clinical instruction. It will be allowed that within the compass of the clinical years it is impossible to secure for the student the opportunity of personally seeing in the wards everything which is desirable for his full instruction, and although the efforts of art be rated at a less value than the productions of nature they have their worth; and certainly they are more impressive than words printed in a book or spoken from a rostrum. Yet again, it is rare that the clinical teacher can command a patient who illustrates all the relevant objective facts which are essential to the instruction of the student, and the collection of a group of patients who together construct a complete exhibition is a happy chance rather than a frequent experience. Pictures representing various clinical conditions may in large measure remedy these defects. What the patient does not show the picture may effectively illustrate. To this end, however, such pictures must be readily available and in a form in which they can be handled without risk of damage. The atlas even if at hand gives but a passing glimpse, and its owner is not unnaturally concerned for its safety. Hence although authors and publishers have spent both effort and skill in the making of effective pictures, and although the teaching value of these will not be contested, their values are but little utilised. Their opportunity for wide service is the clinical picture gallery where they both tell a daily lesson and stand ready to lend aid and emphasis and supplement to bedside teaching.

Questions of space and of expense of course arise. A special gallery is the desirable arrangement and the educational value of the plan is worth some effort and money. Far be it from me to grudge the pathological museum its place but the presentation in permanent form of clinical facts may surely assert an equal claim. If an arranged gallery is not possible the walls of class rooms and of corridors offer themselves as giving at least some service. The framing and glazing need be no serious charge and many pictures can be obtained at small expense, some of them alas! from second-hand bookshops and others from shelves where disturbance is infrequent. With the chances of service offered by the clinical picture gallery many would doubtless come into the open, and additions would be made to their number.

Pictures of course suggest the difficulty of "hanging" and in the present instance of mobility, for one of their fields of opportunity is to attend demonstrations in the class rooms and hospital wards. The simplest and most effective way (I speak from some years' practical experience) is to frame all the pictures of one and the same size (or in groups in which the size of each unit is uniform) and to support them not by "hanging" but by "beads" arranged on the wall in such a fashion that any picture can be taken out or put back again without the slightest difficulty. In this fashion the picture lies flat against the wall, is effectively displayed, can be taken away when wanted and is little likely to be damaged, while space is economised and re-grouping is readily possible.

Education by "pictures" has become a common experience in recent years and probably the moving and even perhaps the speaking variety may find a growing place in the training of the medical student. All the same there is a particular value in the more commonplace picture - the picture which offers a daily message, can be seen at any time, and is one of the earliest and most effective methods of telling a story and producing a permanent memory and possession. These results can be obtained for the medical student by the establishment in his medical school of a clinical picture gallery. 